\title{
Neutrophil Actin Dysfunction Is a Genetic Disorder Associated with Partial Impairment of Neutrophil Actin Assembly in Three Family Members
}

\author{
Frederick S. Southwick, " Guissou A. Dabiri, ${ }^{\star}$ and Thomas P. Stossel ${ }^{\ddagger}$ \\ * Department of Infectious Diseases, University of Pennsylvania School of Medicine, Philadelphia, Pennsylvania 19104; and \\ ${ }^{\ddagger}$ Hematology-Oncology Unit, Massachusetts General Hospital, Boston, Massachusetts 02114
}

\begin{abstract}
A male infant with a severe neutrophil motility disorder and poorly polymerizable actin in PMN extracts was reported over a decade ago to have neutrophil actin dysfunction (NAD) (1974. N. Engl. J. Med. 291:1093-1099). Polymerized actin (F-actin) content of fixed and permeabilized intact neutrophils from the father, mother, and sister of the NAD index case have been measured using nitrobenzoxadiazole-phallacidin, a fluorescent compound which binds specifically to actin filaments. F-actin content of unstimulated PMN from all three family members was significantly lower than unstimulated control PMN (mean 23.6 \pm 0.4 SEM fluorescent units vs. 32.6 \pm 0.6 for controls). After stimulation with the chemotactic peptide FMLP, maximal F-actin content of NAD family member PMN was below that of controls $(52.7 \pm 1.3$ vs. $72.6 \pm 1.8)$. Factin content of detergent insoluble cytoskeletons after stimulation with FMLP was also significantly lower in PMN from NAD family members as compared with controls $(21 \pm 6 \%$ vs. $73 \pm 8 \%)$. PMN extracts from the father and mother, when treated with $0.6 \mathrm{M} \mathrm{KCl,} \mathrm{polymerized} \mathrm{half} \mathrm{as} \mathrm{much} \mathrm{actin} \mathrm{as}$ controls. Whereas diisopropylfluorophosphate treatment of normal PMN decreased actin polymerizability in cell extracts, this treatment increased the assembly of actin in parental PMN extract. Addition of purified actin to NAD extracts failed to reveal an abnormal actin polymerization inhibitory activity, and no obvious structural defect in actin purified from the father's PMNs was noted by HPLC and two dimensional thin layer chromatography of tryptic digests. The present studies of actin assembly in intact PMNs confirm that NAD is associated with a true defect in PMN actin assembly and is a genetic disorder that is recessively inherited.
\end{abstract}

\section{Introduction}

In 1974, Boxer et al. (1) published a case report describing a male infant who suffered from recurrent bacterial infections. The infant's PMNs were severely defective in their ability to migrate and to ingest particles. Whereas most of the actin in $0.6 \mathrm{M} \mathrm{KCl}$ extracts prepared from normal PMNs assembled into sedimentable filaments, only a small fraction of the pa-

Research abstracts previously published in Clin. Res. (1981, 29:397A and 1986, 34:533A).

Please address all correspondence to Dr. Frederick S. Southwick, Department of Infectious Diseases, 536 Johnson Pavilion/G-2, University of Pennsylvania School of Medicine, Philadelphia, PA 19104.

Received for publication 26 January 1988 and in revised form 13 June 1988.

J. Clin. Invest.

(c) The American Society for Clinical Investigation, Inc. 0021-9738/88/11/1525/07 \$2.00

Volume 82, November 1988, 1525-1531 tient's PMN actin polymerized. This finding raised the possibility that a disorder of PMN actin function might be the cause of this profound defect in granulocyte motility.

Here we have documented partial impairment of actin assembly in PMN extracts of the parents of this infant. We have also investigated actin assembly in intact PMN and found that resting and maximal actin filament concentrations after chemotactic stimulation were lower than normal in PMNs from three family members. These findings confirm a true defect in neutrophil actin assembly and indicate that neutrophil actin dysfunction (NAD) ${ }^{1}$ is a recessively inherited disease.

\section{Methods}

\section{Patients}

Family members of the index case of NAD included the father (age 42), the mother (age 41), and two sisters (ages 18 and 15). Except for the father, who has insulin-dependent diabetes mellitus, all members of the family were healthy. None of the index case's relatives had a history of recurrent infections. All family members had normal peripheral granulocyte counts. The mother's and father's PMNs demonstrated normal phagocytosis (1). The younger sister on one occasion developed nausea and light-headedness during venipuncture; therefore, her neutrophils were not used for any of the present studies.

\section{Isolation of human granulocytes}

These studies were reviewed and approved by the appropriate review boards of the institutions participating. Whole blood samples were drawn from patients and healthy controls. $20 \mathrm{~cm}^{3}$ of each blood sample was anticoagulated with citric acid/trisodium citrate/dextrose 5 $\mathrm{cm}^{3}$ of solution containing $0.8 \mathrm{~g} / \mathrm{dl}$ citrate, $2.2 \mathrm{~g} / \mathrm{dl} \mathrm{Na}$ citrate, and 2.45 $\mathrm{g} / \mathrm{dl}$ glucose. Samples were then subjected to dextran sedimentation for $60 \mathrm{~min}$ by addition of $7 \mathrm{~cm}^{3}$ of $2 \mathrm{~g} / \mathrm{dl} \mathrm{T}-500$ dextran (Pharmacia Fine Chemicals, Piscataway, NJ) in a $0.15-\mathrm{M} \mathrm{NaCl}$ solution. The resulting supernatant solution was diluted with $0.15 \mathrm{M}$ saline and centrifuged at $250 \mathrm{~g}$ for $10 \mathrm{~min}$. The cell pellet was then washed twice in $30 \mathrm{vol}$ of $0.15 \mathrm{M} \mathrm{NaCl}$ solution and centrifuged at $250 \mathrm{~g}$ for $10 \mathrm{~min}$. This method yielded white blood cell preparations containing $80-85 \%$ PMNs. The remaining cells were lymphocytes and monocytes. In some preparations PMNs were purified from citrate anticoagulated whole blood using Ficoll sodium diatrizoate solution according to the method of Boyum (2). This method yielded 95-98\% PMNs, the other cells being monocytes and lymphocytes.

For FACS analysis of nitrobenzoxadiazole (NBD)-phallacidinstained PMNs, $6 \mathrm{ml}$ of venous blood was drawn into syringes containing $0.4 \mathrm{ml}$ of $10 \mathrm{~g} / \mathrm{dl}$ EDTA in distilled water. Red blood cells were lysed by the addition of $34 \mathrm{~cm}^{3}$ distilled water, followed immediately

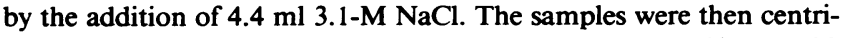
fuged at $400 \mathrm{~g}$ for $5 \mathrm{~min}$. Cells were resuspended in modified HBSS (138 mM NaCl, $6 \mathrm{mM} \mathrm{KCl,} 1.2 \mathrm{mM} \mathrm{MgSO}_{4}, 5 \mathrm{mM} \mathrm{NaHCO}_{3}, 0.64$ $\mathrm{mM} \mathrm{Na}_{2} \mathrm{HPO}_{4}$ [pH 7.4], $0.66 \mathrm{mM} \mathrm{KH}_{2} \mathrm{PO}_{4}, 5.6 \mathrm{mM}$ glucose, and 20 $\mathrm{mM}$ Hepes) and centrifuged at $400 \mathrm{~g}$ for $5 \mathrm{~min}$. This procedure was repeated once and cells resuspended in modified HBSS to achieve a

1. Abbreviations used in this paper: DFP, diisopropylfluorophosphate; NAD, neutrophil actin dysfunction; NBD, nitrobenzoxadiazole. 
final concentration of $1.5 \times 10^{6} \mathrm{cells} / \mathrm{ml}$. On average these preparations contained a mixture of $83 \pm 1.4 \%$ (mean \pm SEM) PMNs, $11 \pm 1.7 \%$ lymphocytes, and $5.1 \pm 0.8 \%$ monocytes as determined by Wright stain (nine determinations). Platelets were not seen on any of these smears. This method was developed to minimize handling of cells and reduce the likelihood of inadvertent PMN activation before stimulation with the agonist (3). Cells were maintained at room temperature, and all experiments were performed within $3 \mathrm{~h}$ of venipuncture.

For the Triton-insoluble cytoskeleton assay PMNs were also suspended in modified HBSS. $\mathrm{CaCl}_{2}$ (final concentration of $1 \mathrm{mM}$ ) was added to cell suspensions $10 \mathrm{~min}$ before cell stimulation unless otherwise noted in the text.

\section{Preparation of granulocyte extracts}

Granulocytes packed by centrifugation were suspended in an equal volume of $0.15 \mathrm{M} \mathrm{NaCl}$ to which was added 15 vol deionized water. They were then immediately centrifuged for $10 \mathrm{~min}$ at $250 \mathrm{~g}$. This step lysed most erythrocytes. The granulocytes were next suspended in homogenization buffer containing 0.34 sucrose, $5 \mathrm{mM}$ DTT, $5 \mathrm{mM}$ ATP, $5 \mathrm{mM}$ EGTA, and $20 \mathrm{mM}$ imidazole- $\mathrm{HCl}$, pH 7.5. The cells were then broken at ice bath temperature by $60-120$ strokes with a tight-fitting pestle in a glass Dounce homogenizer (Kontes Co., Vineland, NJ). This procedure ruptured $>90 \%$ of all cells as monitored by phase contrast microscopy. The resulting homogenates were centrifuged at $12,000 \mathrm{~g}$ for $30 \mathrm{~min}$, yielding a clear supernatant, designated granulocyte extract. This supernatant solution had a pH of 6.8-7.1, which was adjusted to 7.5 by the addition of a few drops of $0.1 \mathrm{M}$ sodium hydroxide. The final protein concentration of the granulocyte extracts varied between 3 and $8 \mathrm{mg} / \mathrm{ml}$. In some experiments cells were treated with $5 \mathrm{mM}$ diisopropylfluorophosphate (DFP) as described by Amrein and Stossel (4) before homogenization. For studies of actin polymerization inhibitory activity (see Table II), granulocyte extracts were depleted of native actin by the addition of a final concentration of $0.6 \mathrm{M}$ $\mathrm{KCl}$ and then were incubated for $2 \mathrm{~h}$ at $25^{\circ} \mathrm{C}$ and centrifuged at $100,000 \mathrm{~g}$ for $2 \mathrm{~h}$. The resulting supernatant was dialyzed against buffer B, containing $0.5 \mathrm{mM}$ ATP, $1 \mathrm{mM}$ DTT, $1 \mathrm{mM}$ EGTA, and 10 $\mathrm{mM}$ imidazole-HCl, $\mathrm{pH} \mathrm{7.5,} \mathrm{before} \mathrm{the} \mathrm{addition} \mathrm{of} \mathrm{purified} \mathrm{rabbit}$ skeletal muscle actin.

\section{Purification of granulocyte actin}

Granulocyte extracts were diluted 1:1 with a solution containing 0.75 $M$ guanidine hydrochloride, $30 \%$ glycerol, $1 \mathrm{mM} \mathrm{CaCl}_{2}$, and $0.5 \mathrm{M}$ sodium acetate buffer, pH 8 (buffer A). The extracts were then passed through a $1 \times 12-\mathrm{cm}$ DNase-Sepharose column prepared as described by Lazarides and Lindberg (5). The column was first eluted with three column volumes of $0.75 \mathrm{M}$ guanidine hydrochloride in buffer $\mathrm{A}$. This was followed by elution with $3 \mathrm{M}$ guanidine hydrochloride in buffer $\mathrm{A}$. 6-ml fractions were collected, dialyzed against 1,000 vol cold deionized water for 18-24 h, and lyophilized. All procedures were performed at $4^{\circ} \mathrm{C}$. The purity of the actin samples was assessed by SDS-PAGE.

\section{Peptide mapping of granulocyte actin}

300-700 $\mu \mathrm{g}$ DNase I affinity-purified PMN actin was oxidized with performic acid and digested with a 1:50 wt/wt ratio of trypsin to actin for $2 \mathrm{~h}$ at $37^{\circ} \mathrm{C}(6)$ (L-1-tosylamido-2-phenylethyl chormethyl ketonetreated trypsin; Worthington Biochemical Corp., Freehold, NJ). The lyophilized digest was dissolved in $0.5 \mathrm{ml}$ of $10 \%$ acetonitrile $/ 0.1 \%$ trifluoroacetic acid and applied to a $14 \times 300$-mm C-18 Bondapack steel column (Waters Associates, Milford, MA). The column was then eluted with a linear gradient of $10-50 \%$ acetonitrile over $60 \mathrm{~min}$. The flow rate was $1 \mathrm{ml} / \mathrm{min}$. Two-dimensional thin layer chromatography of purified PMN actin was performed exactly as described by Elder et al. (7).

\section{Two-dimensional gel electrophoresis}

Two-dimensional gel electrophoresis was performed as described by O'Farrell (8). Isoelectric focusing was performed using $9 \mathrm{M}$ urea, $0.6 \%$ pH 3-10, and $1.4 \%$ pH 4-6 ampholines.

\section{Measurement of actin polymerization in granulocyte extracts}

Sedimentation assay. Granulocyte extracts were made $0.6 \mathrm{M}$ with $3 \mathrm{M}$ potassium chloride and incubated $2 \mathrm{~h}$ at $25^{\circ} \mathrm{C}$. Samples were then centrifuged at $160,000 \mathrm{~g}$ for $30 \mathrm{~min}$ in an air-driven centrifuge (Airfuge; Beckman Instruments, Inc., Palo Alto, CA). Under these conditions globular molecules with molecular weights $\geq 600,000-700,000$ would be expected to sediment. To determine the amount of actin that had sedimented, protein concentrations of the starting solution and the supernatant after centrifugation were determined using the biuret method (9). The fraction of total protein representing actin was determined by quantitative densitometry of Coomassie Blue-stained polyacrylamide gels after electrophoresis of the solutions in SDS.

Viscometry assay. Specific viscosities of purified actin subjected to polymerizing ionic conditions in granulocyte extracts were measured with semimicroviscometers (extra low charge, size 100; Cannon Instrument Co., State College, PA) as previously described (10).

\section{Measurement of actin filament assembly in intact PMNs}

$N B D$-phallacidin assay. $0.5 \mathrm{ml}$ of cell suspensions $\left(0.75 \times 10^{6}\right.$ cells/ sample) were incubated for $7 \mathrm{~min}$ at $25^{\circ} \mathrm{C}$. $0.5 \mathrm{ml}$ of a $1 \times 10^{-6} \mathrm{M}$ FMLP solution or buffer was added to each sample. The reaction was stopped by addition of $0.1 \mathrm{ml}$ of $37 \%$ formaldehyde. Cells were incubated in fixative for $15 \mathrm{~min}$ at $25^{\circ} \mathrm{C}$ before staining for $\mathrm{F}$-actin according to the method of Howard and Oresajo (11). $50 \mu \mathrm{l}$ of modified HBSS containing $3.46 \times 10^{-6} \mathrm{M}$ NBD-phallacidin and $2.1 \mathrm{mg} / \mathrm{ml}$ lysophosphatidal choline were added to the fixed cell preparations, which were then mixed and incubated for $10 \mathrm{~min}$ at $37^{\circ} \mathrm{C}$ and then centrifuged at $12,000 \mathrm{~g}$ for $1 \mathrm{~min}$. Supernatants were removed and pellets suspended in $1.5 \mathrm{ml}$ of modified HBSS.

Stained cells were analyzed as previously described (3). Briefly, the intracellular fluorescence was determined by a Spectrum III flow cytometer (Ortho Diagnostic Systems Inc., Westwood, MA) equipped with an argon laser (488 emission, $500 \mathrm{~mW}$ output). All intensities of cellular fluorescence were recorded on the linear scale ranging from 0 to 255 channels. Intensity values were standardized daily using fluorescent polystyrene spheres. Fluorescent histograms plotting cell number (vertical axis) vs. fluorescence channel (horizontal axis) were recorded for each sample. In all instances the histograms yielded a normal distribution (the peak fluorescence channel corresponded to the mean fluorescence). An average of 5,000-10,000 PMNs per sample were analyzed. PMN F-actin content was expressed as mean fluorescence intensity. Gain settings were identical for patient and control PMNs. Unstimulated values were comparable when cells were incubated in modified HBSS or $0.01 \%$ DMSO (the highest concentrations used in our experiments) in modified HBSS.

Actin association with the Triton-insoluble cytoskeleton. A modification of the method described by White et al. (12) was used. Human PMNs were purified on Ficoll/Hypaque gradients as described above, suspended in modified HBSS, centrifuged at $400 \mathrm{~g}$, and resuspended in the same buffer to achieve a final concentration of $1.5 \times 10^{7}$ cells $/ \mathrm{ml}$. $500 \mu \mathrm{l}$ of the cell suspension was added to $55 \mu \mathrm{l}$ of a $5 \times 10^{-6} \mathrm{M}$ FMLP solution. The reaction was stopped by the addition of $65 \mu \mathrm{l}$ of a solution containing $10 \%$ Triton X-100, $0.075 \mathrm{mg} / \mathrm{ml}$ benzamidine, 0.04 $\mathrm{mg} / \mathrm{ml}$ aprotinin, $0.01 \mathrm{mg} / \mathrm{ml}$ leupeptin, $1 \mathrm{mM}$ PMSF, $54 \mathrm{mM}$ Pipes, $22.5 \mathrm{mM}$ Hepes, $9 \mathrm{mM}$ EGTA, and $1.8 \mathrm{mM} \mathrm{MgCl}$.

After being mixed by two gentle inversions, the solution was left standing for $2 \mathrm{~min}$ at $25^{\circ} \mathrm{C}$, then centrifuged for $2 \mathrm{~min}$ at $12,000 \mathrm{~g}$ in an Eppendorf table top centrifuge. The resulting pellet (the Triton-insoluble fraction) was then solubilized in $100 \mu$ l of gel sample buffer containing $8 \mathrm{M}$ urea, $10 \mathrm{~g} /$ liter SDS, $20 \mathrm{~g} /$ liter $\beta$-mercaptoethanol, 100 $\mathrm{g} /$ liter sucrose, and $0.06 \mathrm{M}$ Tris- $\mathrm{HCl}, \mathrm{pH}$ 6.8. The sample was sonicated for 20-30 s using a sonifier, model 200 with a tapered micro tip (Branson Sonic Power Co., Danbury, CT), output 3. Samples were then boiled for $5 \mathrm{~min}$ and electrophoresed into 5-15\% polyacrylamide slab gels. Triton-insoluble cytoskeleton-associated actin was quantified as previously described (13). 


\section{Degranulation}

$2 \times 10^{6}$ PMNs in $900 \mu \mathrm{l}$ of HBSS containing $5 \mu \mathrm{g} / \mathrm{ml}$ cytochalasin B were incubated $7 \mathrm{~min}$ at $37^{\circ} \mathrm{C}$, and then $100 \mu \mathrm{l}$ of buffer or FMLP were added to achieve final concentrations of $10^{-9}$ to $10^{-7} \mathrm{M}$. One sample from each individual was incubated with $10^{-7} \mathrm{M}$ FMLP in the absence of cytochalasin B. After $15 \mathrm{~min}$, samples were centrifuged at $12,000 \mathrm{~g}$ for $1 \mathrm{~min}$ in Eppendorf tubes and the supernatants were frozen at $-70^{\circ} \mathrm{C}$. Total enzyme concentrations were determined from supernatants of PMNs incubated in buffer and then treated with $0.1 \%$ Triton $X-100$. The concentrations of $\beta$-glucuronidase (13) and vitamin $B_{12}$ binding protein (14) in the supernatants were measured as previously described.

\section{Statistical analysis}

The statistical significance of differences between means was analyzed using the nonpaired $t$ test.

\section{Results}

Actin polymerization in granulocyte extracts. When extracts from normal granulocytes were made $0.6 \mathrm{M}$ in $\mathrm{KCl}$, a percentage of the extract actin sedimented when centrifuged at $160,000 \mathrm{~g}$ for $30 \mathrm{~min}$. Since the cell concentration from which extracts were prepared varied considerably among experiments, there was also variation in the granulocyte extract total protein concentration; therefore, the relationship between the extract total actin concentration and actin sedimentability was determined in each experiment. The fraction of sedimented actin was proportional to the total extract actin concentration (Fig. 1). Above a concentration of $2.5 \mu \mathrm{M}$, actin in control extract was detectably sedimentable. The slope of the line relating total concentration of actin to actin filament concentration (sedimented actin) was $\mathbf{0 . 8 3}$. Under these same conditions the viscosity of the extract as well as its flow birefringence have been shown to increase (10). These findings are all consistent with the assembly of actin into linear filaments rather than nonspecific aggregation, and suggest that the increase in sedimentability of actin reflects actin polymerization. When $\mathrm{KCl}$ was added to granulocyte extracts of the parents of the patient described by Boxer et al. (1), the concentration at which actin was detectably polymerized was $5.2 \mu \mathrm{M}$ (twice the control value) and the slope of the line relating total actin to F-actin

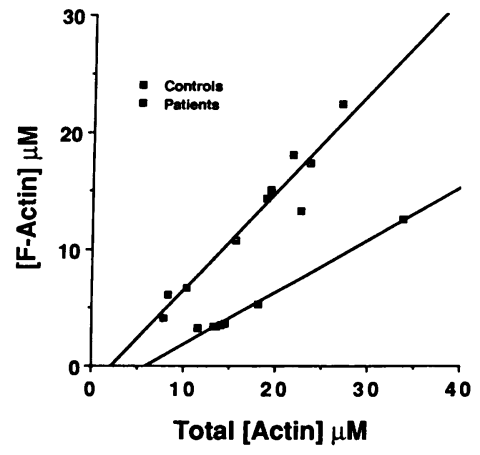

Figure 1. Actin filament concentration as a function of total actin concentration in PMN extracts. PMN extracts were diluted with varying amounts of homogenization buffer, then made $0.6 \mathrm{M}$ with $3 \mathrm{M} \mathrm{KCl}$ and incubated at $25^{\circ} \mathrm{C}$ for $2 \mathrm{~h}$. Samples were then centrifuged at $160,000 \mathrm{~g}$ for $30 \mathrm{~min}$. The actin concentrations of the solutions before and after centrifuga-

tion were measured as described in the methods. Open squares, control PMN extracts, solid squares, PMNs from the mother and father of the NAD index case. The slopes of the lines relating total actin to sedimentable actin (actin filaments) was 0.83 for controls and 0.44 for the NAD parents.

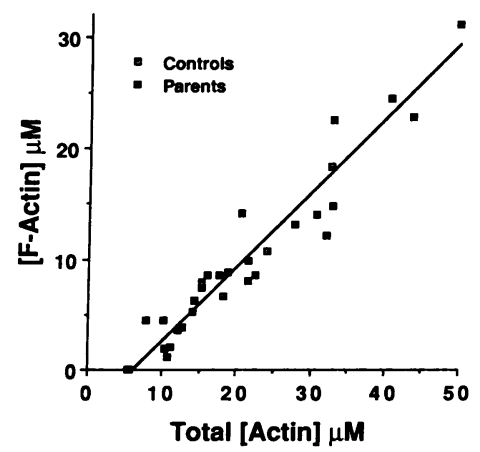

Figure 2. Actin filament concentration as a function of total actin concentration in extracts prepared from PMNs that were treated with DFP. PMNs from controls (open squares) and the NAD parents (solid squares) were treated with $5 \mathrm{mM}$ DFP for $5 \mathrm{~min}$ before homogenization. After this treatment cell extracts were prepared and analyzed as described in Fig. 1. Both control and NAD parent extracts demonstrated similar steadystate F-actin concentrations as measured by sedimentation. The slope of the line relating total to sedimentable actin was 0.67 .

concentration was 0.44 (approximately one-half of control value) (Fig. 1). The percentages of the total protein represented by actin in parental and control extracts were comparable. No increase in the concentration of the 33,000 -mol wt polypeptide generally associated with actin proteolysis was observed in extracts prepared from NAD parent PMNs.

Reaction of control PMNs with DFP before preparation of extract increased the total concentration of actin required before actin filaments began to form (5.1 vs. $2.5 \mu \mathrm{M}$ for PMNs not treated with DFP). The slope of the line relating total to F-actin concentration was also affected by DFP, decreasing from 0.83 to 0.67 . In contrast, when granulocytes from the parents were treated with DFP, extract actin polymerization improved so that it was no longer different from normal cells (Fig. 2).

Actin polymerization in intact PMNs. Actin polymerization in intact PMNs of the parents and sister of the infant was assessed by NBD-phallacidin staining. PMNs from the father, mother, and older sister of the original infant had significantly lower resting concentrations of F-actin (mean F-actin content 23.6 \pm 0.4 fluorescence units, $S E M$ ) as compared with controls (mean 32.6 \pm 0.6 fluorescence units, SEM 10 controls) ( $P$ $<0.001)$. An increase in F-actin content was induced by exposure of PMNs to FMLP $\left(5 \times 10^{-7} \mathrm{M}\right)$ for $30 \mathrm{~s}$ in both

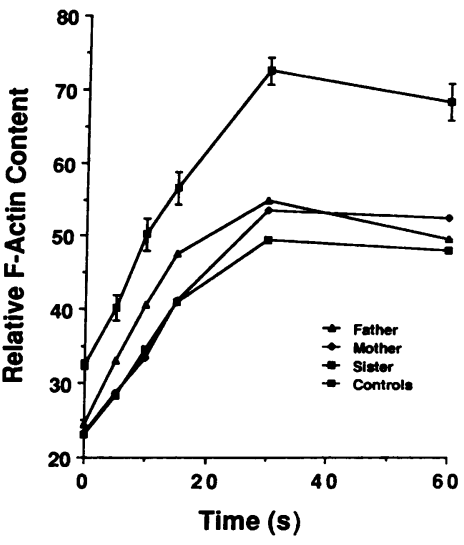

Figure 3. Early time course of the changes in relative $F$ actin content in human PMNs from controls and NAD family members after exposure to FMLP. PMNs were exposed to $5 \times 10^{-7}$ M FMLP at time $=0 \mathrm{~s}$, at $25^{\circ} \mathrm{C}$. At the indicated times cells were fixed with $3.7 \%$ formalin, lysed, stained, and analyzed by FACS for relative F-actin content. The bars on control PMN data points represent the mean \pm SEM of 10 separate experiments. Both prestimulated (0-s time point) and stimulated peak F-actin content (30 s) of PMNs from the father (closed triangles), mother (closed diamonds), and older sister (closed squares) were significantly lower than control values (open squares) $(P<0.001)$. 


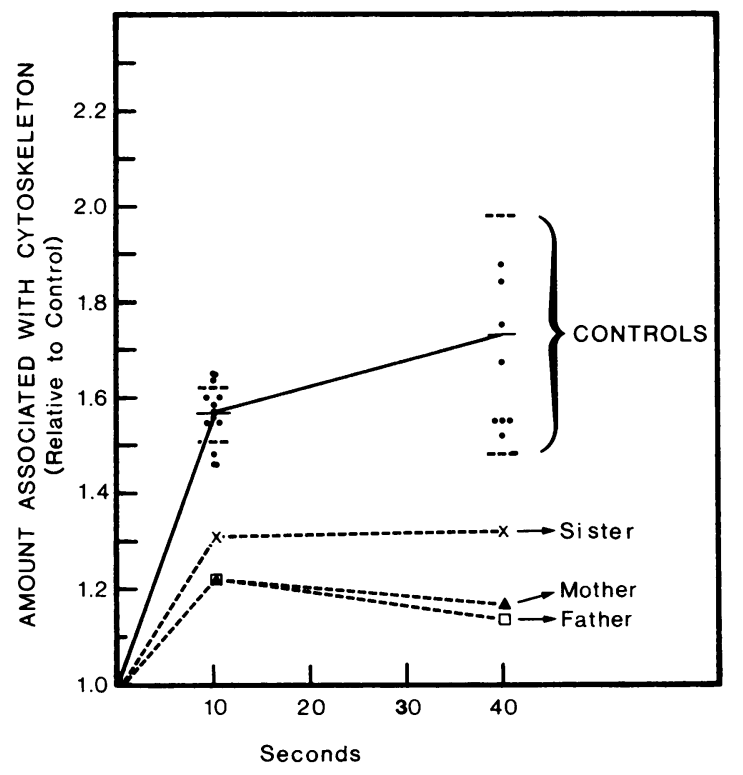

Figure 4. Time course of changes in Triton-cytoskeleton-associated PMN actin in control and NAD family members after FMLP stimulation. PMNs were exposed to $5 \times 10^{-8} \mathrm{M} F M L P$ at time $=0 \mathrm{~s}$, at $37^{\circ} \mathrm{C}$. At the indicated times, the Triton solution was added to the PMN mixture. After centrifugation at $12,000 \mathrm{~g}$ the pellets were solubilized in gel sample buffer and subjected to SDS-PAGE. Triton-associated actin concentration was determined by a laser densitometry. Relative actin concentration was determined by dividing stimulated integration values by unstimulated values as described in Methods. The father, mother, and older sister all had significantly lower stimulated Triton-insoluble actin content at both $10 \mathrm{~s}(P<0.001)$ and $40 \mathrm{~s}$ $(P<0.001)$ as compared with controls. Solid circles, individual control values; solid line, the mean of those values; dashed lines, SD.

patients and controls (Fig. 3). The extent of elevation in Factin concentration was significantly less in PMNs from the mother, father, and sister (mean 52.7 \pm 1.3 ) as compared with control cells (mean $72.6 \pm 1.8$ fluorescence units, SEM, $n=10$ ) $(P<0.001)$. All patient values were significantly lower than controls $(P<0.01)$. The mean rates of actin assembly were also determined by measuring the change in PMN F-actin content during the first $15 \mathrm{~s}$ of FMLP stimulation. The rise in F-actin content was constant with time during this period (Fig. 3). Patient and control cells had roughly comparable actin polymerization rates (patient mean rate: $4.5 \pm 0.3 \% / \mathrm{s}$ vs. control: $4.1 \pm 0.2 \% / \mathrm{s}, P>0.10)$.

Actin filament assembly in intact PMNs was also assessed by measuring the concentration of actin associated with the Triton-insoluble cytoskeleton before and after stimulation with FMLP. As shown in Fig. 4, both the parents and sister demonstrated abnormal actin filament assembly as compared with controls. After $10 \mathrm{~s}$ stimulation with FMLP $\left(5 \times 10^{-8} \mathrm{M}\right)$, the concentration of actin associated with the Triton-insoluble cytoskeleton increased $23 \%$ in the parents' PMNs (1-1.23) and $32 \%$ in the sister's cells $(1-1.32)$. F-actin content in control PMNs increased by an average of $57 \%(1-1.57 \pm 0.02$ SEM, $n$ $=11)$. Control cells continued to increase their F-actin content between 10 and $40 \mathrm{~s}$ stimulation $(1.73 \pm 0.08 \mathrm{SEM}, n=9)$ while F-actin content remained low in the father, mother, and sister $(1.14,1.17$, and 1.32 , respectively). Actin content of PMN cytoskeletons from NAD family members were significantly lower than controls at both 10 and $40 \mathrm{~s}(P<0.001)$. Analysis of whole cell SDS-PAGE (see Methods) revealed comparable total actin concentrations in patient and control PMNs. There was no evidence of increased actin fragmentation in NAD-related PMN samples. Treatment of patient PMN with DFP before chemotactic stimulation did not enhance actin filament assembly.

In addition to actin, the relative concentrations of nine other oligopeptide bands visualized on one-dimensional SDSPAGE were quantitated in control Triton-insoluble PMN cytoskeletons and these values compared with PMN from NAD family members (Fig. 5). Significantly higher concentrations of a 54,000-mol wt protein were found in the Triton-insoluble fractions of the mother's and older sister's PMNs (mother: mean $9.2 \%$ of the total protein, four determinations; sister: mean $5.4 \%$, two determinations, vs. $3.9 \% \pm 0.2$ SEM, range 2.9-4.6\% for control PMN, $n=9, P<0.001$ and $P=0.012$,

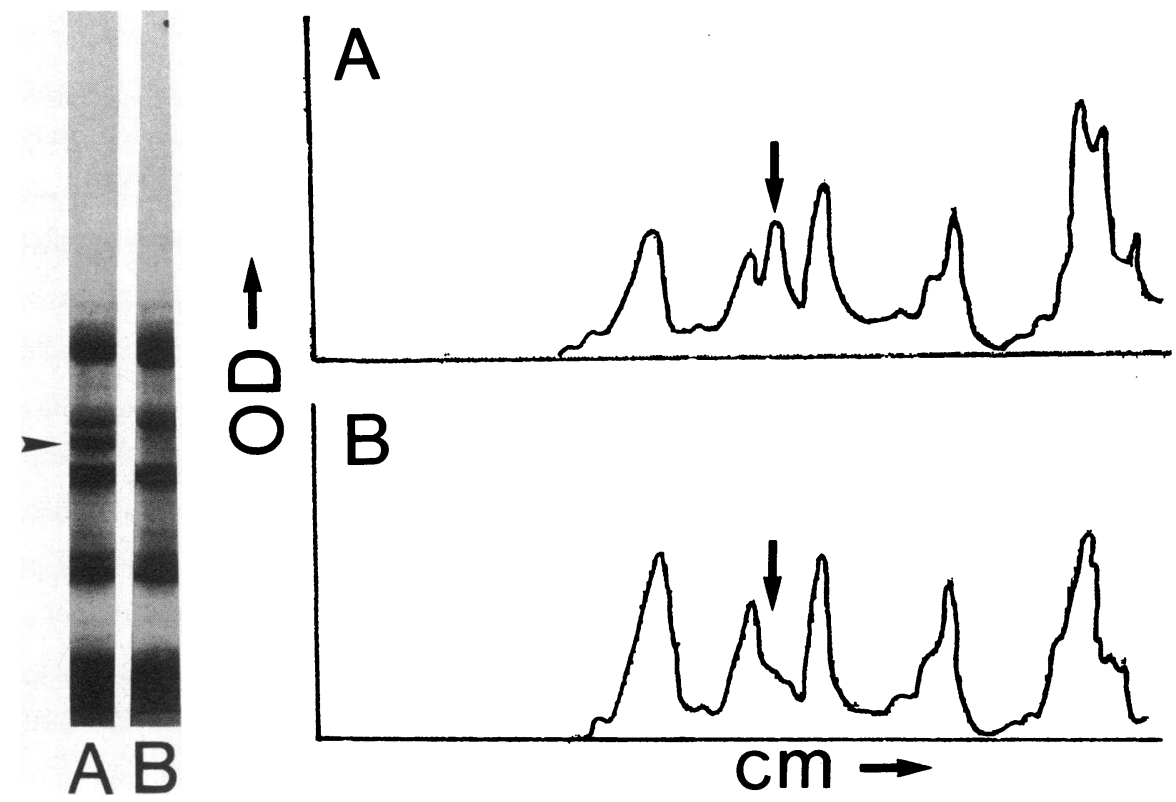

Figure 5. (Left) Coomassie Blue-stained SDS-PAGE of the Triton-insoluble fractions of unstimulated PMNs from the mother of the NAD index case $(A)$ and from a control $(B)$. Samples were prepared as described in Fig. 4. Note the prominent polypeptide band at $54 \mathrm{kD}$ (arrow) not seen in the control sample. (Right) Densitometry scans of the stained SDS-PAGE shown on the left. The arrow points to the position of the 54-kD polypeptide. 
respectively). No differences in the concentrations of other cytoskeleton-associated proteins were observed. Neither treatment of PMN with DFP nor stimulation with FMLP significantly altered the concentrations of the $54,000-\mathrm{mol}$ wt protein in the mother's or older sister's PMN Triton-insoluble fractions.

The lower than normal rise in F-actin content associated with FMLP stimulation of PMN from NAD family members did not appear to be caused by a decrease in functional FMLP receptors. FMLP receptor function was assessed using a degranulation assay (Table I). The concentrations of compounds known to be released from primary ( $\beta$-glucuronidase) and secondary (vitamin $B_{12}$ binding protein) granules were measured after PMNs were exposed to increasing concentrations of the peptide $\left(10^{-9}-10^{-7} \mathrm{M}\right)$ in buffer containing cytochalasin $B$. Concentrations of $\beta$-glucuronidase and $B_{12}$ released from the mother's and father's PMNs were similar to control. Compounds released from unstimulated PMNs were also similar in control and parents, suggesting that parental PMN granules were not abnormally fragile. Finally, in the absence of cytochalasin B, degranulation of parental PMNs after exposure to $10^{-7}$ M FMLP did not differ from controls.

Preliminary investigations of the biochemical basis for defective PMN actin assembly. The formidable complexity of polymerization of pure actin compounded by the environment of cell extracts that contain proteins that can promote or inhibit actin assembly $(15,16)$ has made understanding normal PMN extract actin, much less an abnormal PMN actin function, difficult. Because our investigations are inconclusive, they will be only briefly summarized. We investigated the

Table I. Degranulation of PMN from the Father and Mother of the NAD Index Case, after Stimulation with Varying Concentrations of FMLP

\begin{tabular}{lcc}
\hline \multicolumn{1}{c}{ Protein condition:* } & $\beta$-Glucuronidase & Vitamin $\mathbf{B}_{12}$ binding \\
\hline FMLP $\left(10^{-7} M\right)$ & & \\
Mother & $23.9^{\ddagger}$ & 29.4 \\
Father & 35.7 & 33.3 \\
Control & 37.5 & 35.9 \\
FMLP $\left(10^{-8} M\right)$ & & \\
Mother & 10.9 & 18.8 \\
Father & 11.9 & 19.1 \\
Control & 15.0 & 16.1 \\
FMLP $\left(10^{-9} M\right)$ & & 7.9 \\
Mother & 7.1 & 9.2 \\
Father & 7.1 & 9.2 \\
Control & 7.5 & \\
No FMLP & & 6.5 \\
Mother & 8.5 & 10.7 \\
Father & 10.0 & 13.0 \\
Control & 9.5 & 13.8 \\
FMLP $\left(10^{-7} M\right)-$ Cyto B* & 10.0 & 19.9 \\
Mother & & \\
Father & 8.7 & \\
Control & 9.5 & \\
\hline
\end{tabular}

\footnotetext{
* Except where noted, PMNs were treated with a final concentration of $5 \mu \mathrm{g} / \mathrm{ml}$ of cytochalasin B for $7 \mathrm{~min}$ before stimulation. Cells were then incubated for $15 \mathrm{~min}$ with FMLP.

$\ddagger \%$ of total enzyme content (see Methods).
}

possibility of an abnormal actin-modulating protein that might prevent actin monomers or actin oligomers from combining to form filaments in affected cells. As shown in Table II, when granulocyte extract was prepared as described in Fig. 1, the resulting supernatants from control and parental PMN failed to inhibit the polymerization of purified rabbit skeletal muscle actin. If PMNs were first treated with $5 \mathrm{mM}$ DFP before preparation of extracts, an activity that markedly inhibited actin polymerization was observed in both parental and control extracts; however, control extracts demonstrated more inhibition than parental solutions $(0.43 \pm 0.06 \mathrm{SD}$ vs. $0.25 \pm 0.07 \mathrm{SD} \Delta$ viscosity/mg protein).

A defect in the structure of actin might also account for the lower content of PMN actin filaments observed in family members. Two-dimensional electrophoresis revealed comparable concentrations of the characteristic nonmuscle gamma and beta actin species in both control and parent extracts (data not shown). Reverse phase HPLC of tryptic digests of PMN actin, purified by DNAase affinity chromatography from control and the father's cells, revealed similar profiles except for a

Table II. Inhibition of Actin Polymerization by Neutrophil Extracts

\begin{tabular}{|c|c|c|c|}
\hline & $\begin{array}{c}\text { Extract } \\
\text { concentration }\end{array}$ & $\begin{array}{l}\text { Specific } \\
\text { viscosity }\end{array}$ & $\begin{array}{l}\text { Decrease specific } \\
\text { viscosity/mg protein }\end{array}$ \\
\hline & $m g / m l$ & & \\
\hline \multicolumn{4}{|l|}{ No DFP } \\
\hline Father & 3.7 & 0.80 & $0.00^{*}$ \\
\hline Mother & 4.7 & 0.50 & 0.02 \\
\hline Control & 2.8 & 0.64 & 0.00 \\
\hline Actin in buffer & - & 0.54 & - \\
\hline \multicolumn{4}{|l|}{ DFP } \\
\hline \multirow[t]{2}{*}{ Father } & 3.1 & 0.41 & 0.16 \\
\hline & 1.6 & 0.46 & 0.21 \\
\hline \multirow[t]{2}{*}{ Mother } & 3.4 & 0.20 & 0.33 \\
\hline & 1.7 & 0.41 & 0.29 \\
\hline \multicolumn{4}{|l|}{ Controls } \\
\hline 1 & 3.8 & 0.06 & 0.40 \\
\hline \multirow[t]{2}{*}{2} & 3.4 & 0.06 & 0.45 \\
\hline & 1.7 & 0.28 & 0.52 \\
\hline 3 & 4.7 & 0.05 & 0.33 \\
\hline 4 & 3.6 & 0.04 & 0.44 \\
\hline \multirow[t]{2}{*}{5} & 4.1 & 0.04 & 0.39 \\
\hline & 2.0 & 0.25 & 0.48 \\
\hline 6 & 4.5 & 0.03 & 0.36 \\
\hline 7 & 3.4 & 0.07 & 0.44 \\
\hline 8 & 3.5 & 0.03 & 0.48 \\
\hline Actin in buffer & - & 0.57 & - \\
\hline
\end{tabular}

Extracts were prepared as described in Figs. 1 and 2. PMN actin was polymerized by the addition of a final concentration of $0.6 \mathrm{M} \mathrm{KCl}$ and incubated for $2 \mathrm{~h}$, then centrifuged for $30 \mathrm{~min}$ at $160,000 \mathrm{~g}$. The resulting supernatants were dialyzed against buffer B (see Methods), and then purified rabbit skeletal muscle actin (final concentration, $15 \mu \mathrm{M})$ was added. The solution was then made $0.1 \mathrm{M}$ with a 3-M $\mathrm{KCl}$ stock solution. Samples were incubated $2 \mathrm{~h}$ at $25^{\circ} \mathrm{C}$.

* Calculated by subtracting the viscosity of $15 \mu \mathrm{M}$ purified actin polymerized in extract from the viscosity of the same concentration of actin polymerized in buffer. This difference in viscosity was then divided by the total protein concentration of extract. 


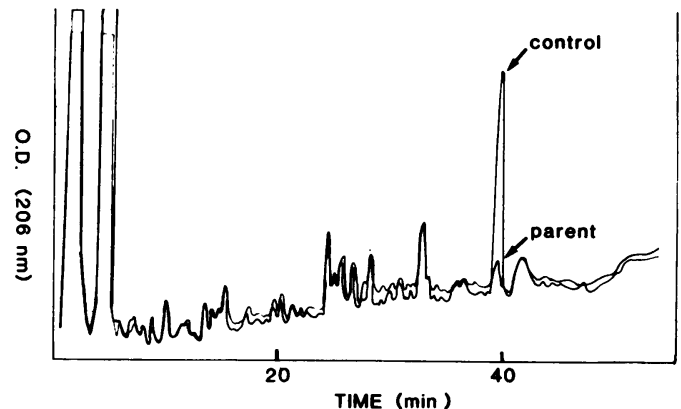

Figure 6. Reverse phase HPLC profiles of oligopeptides derived from tryptic digestion of control and NAD PMN actin purified by DNase I affinity chromatography. Actin was purified from extracts of DFPtreated PMNs from a control and the father of the NAD index case. $300-700 \mu \mathrm{g}$ of actin was oxidized with performic acid and then digested with trypsin as described in Methods. The digested actin was lyophilized, resuspended in $0.5 \mathrm{ml} 10 \%$ acetonitrile $/ 0.1 \%$ trifluoroacetic acid, and applied to a C-18 Bondapack column. The column was then eluted with a linear gradient of 10-50\% acetonitrile over 60 $\mathrm{min}$ at flow rate of $1 \mathrm{ml} / \mathrm{min}$. Absorbance was monitored at $206 \mathrm{~nm}$. The only major difference between patient and control profiles was a prominent peak at $40 \mathrm{~min}$. This fraction was resubjected to trypsin digestion and rechromatographed. The elution profile was identical to control actin, indicating that this peak represented undigested actin.

single peak that eluted at $40 \mathrm{~min}$ (Fig. 6). Exposure of this peptide solution to further trypsin digestion demonstrated that this peak represented undigested actin. Two-dimensional tryptic peptide maps of similarly purified PMN actin from a control and the father also failed to demonstrate any significant differences in the peptide maps (data not shown).

\section{Discussion}

Boxer et al.'s original studies of an infant with a severe neutrophil motility disorder raised the exciting possibility that defective phagocytosis and chemotaxis in this patient's PMNs might be caused by abnormal neutrophil actin assembly (1). NAD remains the only disease thought to be associated with a defect in actin function; therefore, this disorder is of considerable interest not only to neutrophil investigators but also to cell biologists and contractile protein biochemists. The original studies of actin assembly used extracts derived by homogenizing resting neutrophils. It has been suggested that these studies may not accurately reflect the true functional state of actin in intact PMNs. Homogenization may release multiple granule proteins including proteolytic enzymes that may result in damage to actin and actin-modulating proteins. The assay takes several hours to perform; during this time actin function may deteriorate. Finally, maximal stimulation of actin assembly in extracts requires the addition of an unphysiologic concentration of potassium chloride $(0.6 \mathrm{M})(10)$.

To more accurately assess PMN actin function, two assays that are capable of measuring actin filament assembly in intact cells before and after exposure to a physiologic stimulus were used: NBD-phallacidin and actin associated with the Tritoninsoluble cytoskeleton. These studies have demonstrated that both resting and maximal concentrations of actin filaments after chemotactic stimulation are lower than normal in PMNs from the father, mother, and older sister of the original NAD index case. In addition, using the original extract assay of
Boxer et al. (1), a 50\% decrease in actin filament assembly was observed in PMNs from the father and mother. These findings confirm a true defect in neutrophil actin function. The demonstration of partial defects in actin filament assembly in three family members also indicates that NAD is a genetic disorder that is recessively inherited.

The biochemical defect that accounts for decreased neutrophil actin assembly remains to be determined. Investigations of PMN extracts have revealed a proteolytic enzyme-sensitive activity that inhibits actin filament assembly. This activity, however, is lower in PMN extracts from relatives than controls, a condition that would be expected to enhance rather than inhibit actin polymerization. Second, DFP treatment, the condition that maximized inhibitory activity, paradoxically enhanced actin polymerization in the heterozygotes' extracts. This finding suggests the presence of a second protease-sensitive component that promotes actin assembly and is more easily degraded in NAD than in control cells. Such an assembly-promoting activity has recently been described in DFPtreated rabbit peritoneal PMNs (17). This assembly-promoting activity could result from preformed actin filaments whose high affinity ends are uncapped during PMN chemotactic stimulation (17). A subtle, as yet undetected, point mutation in actin rendering the molecules less capable of polymerizing and more susceptible to proteolysis could explain our findings in NAD-related PMNs. A second possibility is that PMNs from this family have an abnormal actin-binding protein important for stimulating actin filament assembly in PMNs. A structural defect in this protein could be associated with an abnormal affinity for actin as well as an increased susceptibility to proteolytic damage. Further progress in understanding this disorder will require a better understanding of the mechanisms by which normal PMNs regulate actin filament assembly (18).

\section{Acknowledgments}

We would like to thank Richard Bringhurst for performing HPLC peptide mapping, Cecilia Slater for purifying PMN actin, Mathew Movesian for performing isoelectric focusing studies, Elizabeth Williams for technical assistance, Tondala Cartwright for degranulation studies, Tom Howard for assistance with the NBD-phallacidin assay, and Rob Roy MacGregor for his helpful advice. Finally, we wish to express our great appreciation to the Schillinger family for their many years of cheerful cooperation and unflagging devotion to this project.

This research was funded by grants Al-23262-02 and HL-19429 from the National Institutes of Health, Bethesda, MD.

\section{References}

1. Boxer, L. A., E. T. Hedley-Whyte, and T. P. Stossel. 1974. Neutrophil actin dysfunction and abnormal neutrophil behavior. $N$. Engl. J. Med. 291:1093-1099.

2. Boyum, A. 1968. Isolation of mononuclear cells and granulocytes from human blood: isolation of mononuclear cells by one centrifugation and of granulocytes by combining centrifugation and sedimentation at 1g. Scand. J. Clin. Lab. Invest. 21:77-89.

3. Shalit, M., G. A. Dabiri, and F. S. Southwick. 1987. Platelet-activating factor both stimulates and "primes" human polymorphonuclear leukocyte actin filament assembly. Blood. 70:1921-1927.

4. Amrein, P. C., and T. P. Stossel. 1980. Prevention of proteolysis of contractile proteins in human polymorphonuclear leukocytes by diisopropylfluorophosphate. Blood. 56:442-447. 
5. Lazarides, E., and U. Lindberg. 1974. Actin is the naturally occurring inhibitor of deoxyribonuclease I. Proc. Natl. Acad. Sci. USA. 71:4742-4746.

6. Hirs, C. H. W. 1956. The oxidation of ribonuclease with performic acid. J. Biol. Chem. 219:611-621.

7. Elder, J. H., R. A. Pickett, II, J. Hampton, and R. A. Lerner. 1977. Radioiodination of proteins in single polyacrylamide gel slices. J. Biol. Chem. 252:6510-6515.

8. O'Farrell, P. H. 1975. High resolution two-dimensional electrophoresis of proteins. J. Biol. Chem. 250:4007-4021.

9. Lowry, O. H., A. J. Rosebrough, A. L. Farr, and R. J. Randall. 1951. Protein measurement with the Folin phenol reagent. J. Biol. Chem. 193:265-275.

10. Southwick, F. S., and T. P. Stossel. 1981. Isolation of an inhibitor of actin polymerization from human polymorphonuclear leukocytes. J. Biol. Chem. 256:3030-3036.

11. Howard, T. H., and C. O. Oresajo. 1985. The kinetics of chemotactic peptide-induced change in F-actin content, F-actin distribution, and the shape of nètrophils. J. Cell Biol. 101:1078-1085.

12. White, J. R., P. H. Naccache, and R. I. Sha'afi. 1983. Stimula- tion by chemotactic factor of actin association with the cytoskeleton in rabbit neutrophils. J. Biol. Chem. 258:14041-14047.

13. Mandell, B. F., D. Ohliger, and J. Rella. 1987. Rapid simultaneous assessment of neutrophil superoxide generation and lysosomal enzyme release. J. Immunol. Methods. 100:211-214.

14. Gottlieb, C., K.-S. Lau, L. R. Wasserman, and V. Herbert. 1965. Rapid charcoal assay for intrinsic factor (IF), gastric juice unsaturated $B_{12}$ binding capacity, antibody to IF and serum unsaturated $B_{12}$ binding capacity. Blood. 25:875-884.

15. Stossel, T. P., C. Caponnier, R. M. Ezzel, J. H. Hartwig, P. A. Jamney, D. J. Kwiatkowski, S. E. Lind, D. B. Smith, F. S. Southwick, H. L. Yin, and K. S. Zaner. 1985. Nonmuscle actin-binding proteins. Annu. Rev. Cell Biol. 1:353-402.

16. Korn, E. D. 1982. Actin polymerization and its regulation by proteins from nonmuscle cells. Physiol. Rev. 62:672-737.

17. Carson, M., A. Weber, and S. H. Zigmond. 1986. An actin-nucleating activity in polymorphonuclear leukocytes is modulated by chemotactic peptides. J. Cell Biol. 103:2707-2714.

18. Harris, H. 1987. Microfilament dynamics, few answers but many questions. Nature (Lond.). 330:310-311. 